\title{
Research on SWMM Runoff Control Index Decomposition Based on Constraint Optimization Method
}

\author{
Shiyuan Huang ${ }^{1, *}$, Pengfei Liu ${ }^{2}$, Hongqin Zhang ${ }^{2}$, and Zhipeng Ding ${ }^{2}$ \\ ${ }^{1}$ School of Civil Engineering,University of South China,Hengyang 421001,China \\ ${ }^{2}$ School of Architecture,University of South China,Hengyang 421001, China
}

\begin{abstract}
The "Sponge City Construction Technical Guide" mentions the method for decomposing and implementing the annual total runoff control rate: volume method and model simulation method. Through research, it is found that the two are based on the control detailed planning level in decomposing the scale parameters of LID facilities. The indicators to each block are allocated through repeated tests through experience and trial calculations, resulting in a lack of scientific rationality in the process and results of the indicator decomposition, and because the Guide is still in the trial stage, there are few researches on the decomposition of runoff control indicators represented by SWMM. Therefore, with the help of MATLAB's constraint optimization module and SWMM hydro-hydraulic model, this study proposes a complete set of decomposition ideas and methods for the decomposition and implementation of the annual runoff total control rate in the special planning of sponge city, and the index decomposition process through relevant cases Elaborate.
\end{abstract}

\section{Introduction}

In December 2013, General Secretary Xi Jinping proposed to build sponge cities that can naturally accumulate, permeate and purify, so as to improve the quality of cities and improve the quality of people's lives, in view of the current water pollution, water shortage, flood and other problems encountered in urban development. In October 2014, the Ministry of Housing and Urban-Rural Development, together with other major design institutes, issued the Technical Guide for Sponge City Construction -- Construction of LowImpact Rainwater System for Development (Trial) (hereinafter referred to as the Guide). The Guide has given four control indexes for different water control problems, among which the total runoff control will directly affect the effectiveness of the other three controls, so the total runoff control can be taken as the primary control object to promote sponge city planning and design. In the actual planning, the annual runoff control rate can be further refined and decomposed into the unit area control volume (comprehensive index) of each sub-plot, and then the comprehensive index can be further refined into single indicator such as sunken green land rate according to the actual situation of the plot ${ }^{[1]}$. All these indicate that the total runoff control rate plays an indispensable leading role in the planning and construction of sponge cities, which is the main line and basis throughout all planning stages. Correctly understand the specific meaning of control index in different planning stages; How to select the relevant control indexes and how to decompose and implement the control indexes has become the key task of further deepening the sponge research.

\section{Decomposition and implementation of indicators at each planning level}

According to the planning principles of protective development, minimization of hydrological interference and overall coordination, the Guidelines put forward corresponding index decomposition methods for different planning levels.

\subsection{Overall planning level}

Explicitly mentioned in the guide overall urban planning to consider the local actual situation, the organization carries out is given priority to with low impact development of related research, put forward the low impact development strategy and objectives, the comprehensive analysis of the rate, building density, space, function layout, etc, on the basis of the total annual runoff control into the overall urban planning level. According to the nature and functional layout of land parcels in the study area, combined with local selfheating geographical conditions, short-term and longterm development planning, location of runoff control zoning map, and comprehensive economic strength, the target of annual runoff control rate is determined. In addition, it is necessary to consider the development intensity, rain pattern and law, abundant water resources and other related factors of the research area.

\footnotetext{
* Shiyuan Huang : 550903597@qq.com
} 
When the above conditions are considered comprehensively, if it is found that the study area does not have the space conditions for runoff control or the reconstruction cost is too high, the annual runoff total control target can be appropriately reduced. At the same time, it should also be noted that the target of runoff control is not as high as possible. Excessive emission reduction of rainwater will cause the water body in the basin to shrink, which is not conducive to the ecological cycle of the rainwater system. When the runoff control rate exceeds a certain level, the economic benefits of investment will decline, which is likely to cause problems such as oversized facilities and waste of resources.

\subsection{The level of controlled detailed planning}

The main task of regulatory detailed planning is to determine the runoff control indicators of each sub-plot, including comprehensive indicators and single indicators. All relevant majors should coordinate with each other at the level of regulatory detailed planning. By analyzing the functional layout, spatial structure, economic strength and other factors of each block in the planning area and combining with the actual runoff management and control ability of each sub-block, the preliminary evaluation of each block is made, and the comprehensive index of each block is determined by weighted accounting. In addition, factors such as building density and green land rate are combined to determine the lowimpact development facilities to be selected, and the runoff control objectives proposed in the previous stage are further decomposed and implemented. Finally, single indicators such as lower concave green land rate are obtained to guide the development and construction of various blocks.

\subsection{Site detail planning level}

Constructional detailed planning shall be made in accordance with the superior plan control requirements, actively coordinate related major, formulate reasonable design scheme, in order to promote regional sustainable development as the goal, the control requirement of specific fulfil LID facilities type and composition, spatial layout, construction scale, construction sequence, funding arrangement, etc.In order to ensure that the runoff discharge after the block development and construction meet the expected runoff control objectives

\subsection{Existing problems}

With the continuous promotion of sponge city construction in the whole country and the deepening of sponge city construction in various regions, the planning and construction ideas of sponge city at various planning levels are also constantly improved. From urban master planning to regulatory detailed planning to constructive detailed planning, how to scientifically and rationally decompose and implement the control indexes of sponge city runoff has always been the focus and difficulty of planning authorities. However, according to the current research results, there are few researches on the decomposition system and methods of the sponge city planning and control index. In Table 3-1, the Guide explains in detail the different control objectives, indicators and corresponding assignment methods at different planning levels. Through practice, it is found that there are still some problems in the decomposition process of control indicators, no matter the trial algorithm or the model method.

\subsubsection{The decomposition process of single index is too complicated}

Index decomposition in regulatory detailed planning can be divided into comprehensive index decomposition and single index decomposition. Related concepts have been described above. In the Guide, two decomposition methods are proposed for single index: trial algorithm and model method. At present, most of the researches are based on trial algorithm, which can't get rid of the disadvantages of trial algorithm, such as tedious calculation process, strong subjectivity, inaccurate decomposition results and so on. The size of the index is based on different LID facilities around the regulatory level decomposition to block index, using the method of volume through experience and trial test repeatedly to allocate $^{[2,3]}$, as long as around the conform to the overall total annual runoff control block shows that the index decomposition conforms to the regulations, in order to meet the assessment requirements, constantly repeated set index, the sponge in the urban planning control index decomposition of assignment process is too complicated.

\subsubsection{The model simulation method is not mature to decompose the index process}

Although it is mentioned in the Guide that qualified cities can decompose and implement the control indicators by means of model simulation, because the Guide is still in the trial stage, it does not give a detailed answer on what model to use and how to use the model to decompose the indicators.Due to the fact that the decomposition of control indicators should be implemented in different scales of LID, and there are few domestic hydrologic models with LID simulation function, SWMM, HSPF, SUSTAIN and other models are widely applied in this field. By reading the literature and practice of SWMM the direction of the research can be found, but the current of SWMM is used to study the urban flood control and drainage ${ }^{[4,5]}$, water environmental governance, rainwater pipe network optimization $^{[6]}$, LID facilities efficiency simulation assessment ${ }^{[7,8]}$. The research on the decomposition of runoff control index in sponge city is almost blank.

\section{Technical route}

In view of the above two problems, this research reference related knowledge, mathematical statistics with 
the help of MATLAB and constrained optimization module of SWMM hydrologic hydraulic model, the special planning of sponge city middle-aged runoff amount control decomposition and implement the system puts forward a set of complete decomposition and the method, hope to be able to deepen the planning of urban special sponge depth, reduce the workload planning personnel, improve the feasibility of runoff control index decomposition results. The decomposition work starts from the overall planning and regulatory detailed planning, and is gradually decomposed according to mandatory indicators, comprehensive indicators and individual indicators (Figure 1).

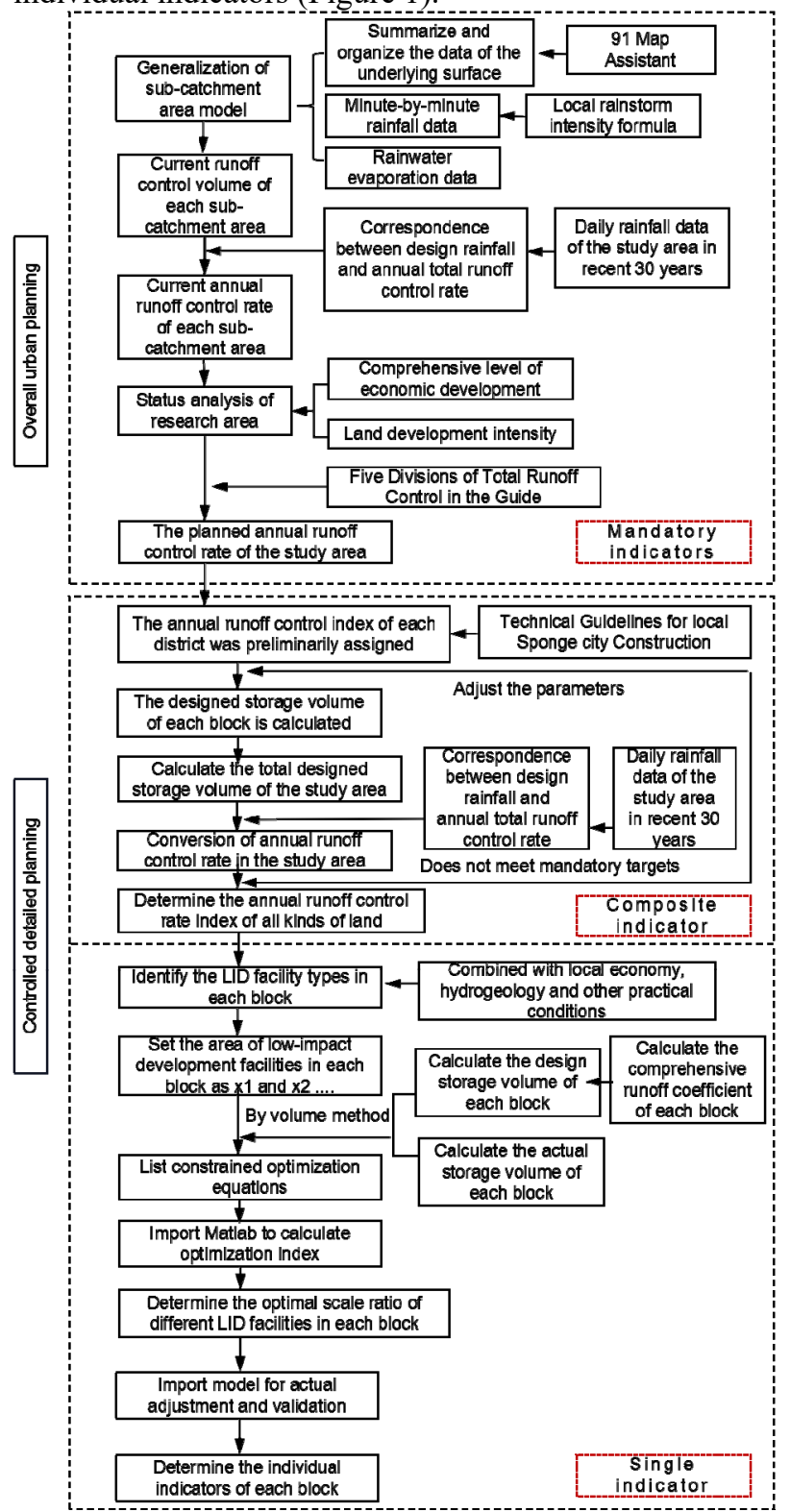

Fig. 1.Road map for Decomposition of Runoff Control Indicators

\section{Case interpretation}

This study takes Hengyang city center as an example. The study area starts from Xiangjiang North Road in the east, Hongxiang North Road in the west, Chuanshan Avenue in the north, and Yancheng Road in the south.
The total planned area is 333.5HA (Figure 2), with residential land as the main land and park land in the south.

\subsection{The determination of the general objective of runoff control at the general planning level}

According to the study of regional soil type, topographic slope, land development nature and intensity, hydrogeology and other factors analysis of the current plot of actual runoff control ability, combined with hengyang city in the runoff control zoning map location, the level of economic development to comprehensively determine the total annual runoff control target (mandatory indicator).

Firstly, basic data should be collected and collated. DEM data of the research area should be obtained through 91 Health map assistant, and relevant parameters such as average slope and area of each sub-catchment area can be obtained through GIS analysis (Figure 3). The impermeable percentage parameters of each subcatchment area required in the model are calculated according to the high-precision remote sensing image, including green space, road, building and water surface area (Figure 4), and obtained through the weighted calculation of the corresponding runoff coefficient. Model simulation required by minute rainfall data is according to hengyang city storm intensity formula fit out of Chicago rain pattern, rainfall design recurrence period for 5 years, peak ratio $\mathrm{r}=0.4$, rainfall lasts 120 minutes, rainfall total of $67.4930 \mathrm{~mm}$ (Figure 5); The houghton model was selected for infiltration, and other relevant parameters were obtained by referring to relevant literature and the value of SWMM model user manual $^{[9-11]}$. Finally, the stormwater model of hengyang central urban area was established (Figure 6). The actual rainfall situation of the model was simulated, the rainwater storage capacity of each sub-catchment area was analyzed, and the rainfall runoff control volume of each block was calculated.

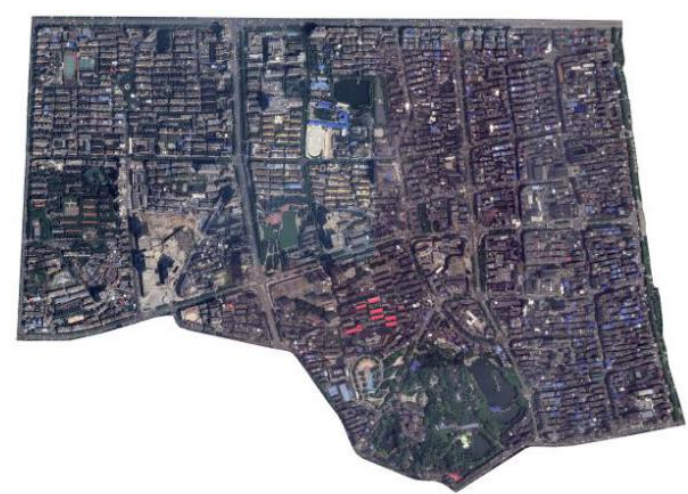

Fig. 2.Image of planning area 


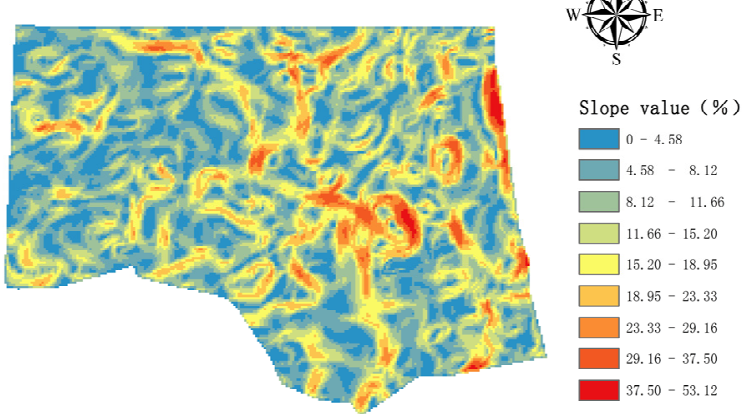

Fig. 3. Slope nephogram of study area

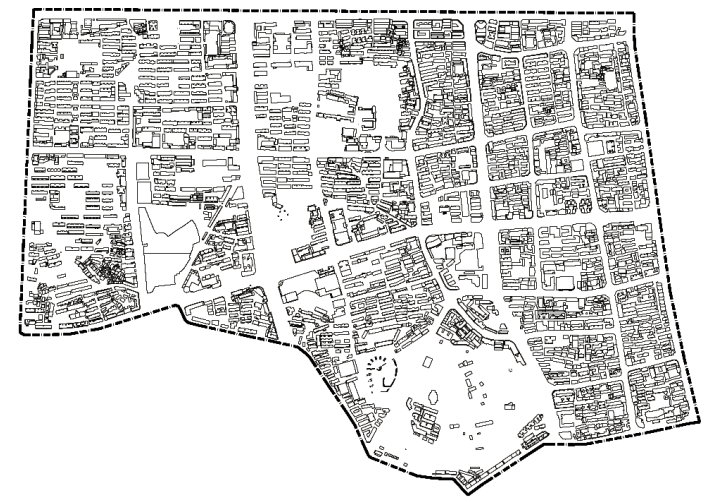

Fig. 4.Interpretation of Buildings in Planning Area

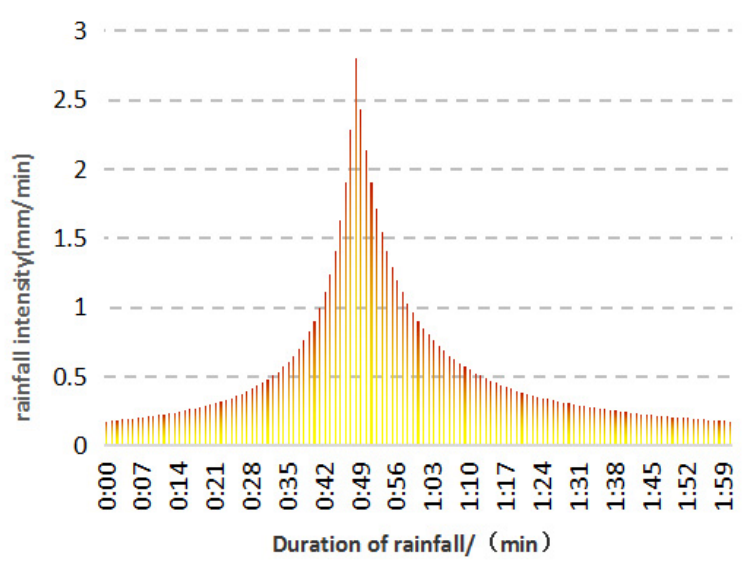

Fig. 5.Ainfall process line of Hengyang rainstorm recurrence period $\mathrm{P}=5 \mathrm{a}$

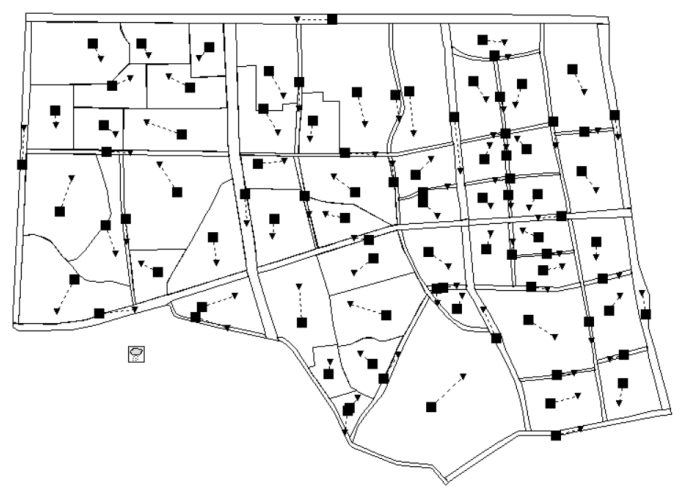

Fig. 6.Overview of SWMM Model in Planning Area
Due to the "Guide" appendix 2 does not give hengyang city annual runoff control rate and its corresponding design rainfall value, considering the different natural conditions of different cities, rainfall characteristics are also different, annual runoff control rate and the corresponding design rainfall should be calculated separately. Reference related literature, from the national meteorological information center web access to hengyang 1989.1.1-2020.4.30 11413 daily rainfall data, according to the guide mentioned ${ }^{[12,13]}$, statistical method combined with linear interpolation method, calculate the hengyang's latest step were $5 \%, 1 \%$ for corresponding design rainfall runoff amount control table values (Table 1 and Table 2), according to the rainfall runoff control volume of each block calculated above, the annual runoff control rate of each block's current status can be obtained by referring to the table (Figure 7).

Table 1. Annual Runoff Total Control Rate with 5\% Step Size and Design Rainfall Value in Hengyang City (1989-2020)

\begin{tabular}{cccc}
\hline $\begin{array}{c}\text { Annual runoff } \\
\text { control rate/\% }\end{array}$ & $\begin{array}{c}\text { Design } \\
\text { rainfall/mm }\end{array}$ & $\begin{array}{c}\text { Annual runoff } \\
\text { control rate/\% }\end{array}$ & $\begin{array}{c}\text { Design } \\
\text { rainfall/mm }\end{array}$ \\
\hline $15 \%$ & 2.1 & $55 \%$ & 10.8 \\
$20 \%$ & 2.8 & $60 \%$ & 12.6 \\
$25 \%$ & 3.6 & $65 \%$ & 14.7 \\
$30 \%$ & 4.6 & $70 \%$ & 17.1 \\
$35 \%$ & 5.6 & $75 \%$ & 20.1 \\
$40 \%$ & 6.6 & $80 \%$ & 23.7 \\
$45 \%$ & 7.8 & $85 \%$ & 28.6 \\
$50 \%$ & 9.2 & $90 \%$ & 35.7 \\
\hline
\end{tabular}

Table 2.Table of Total Annual Runoff Control Rate and Design Rainfall Values for Some 1\% Steps in Hengyang City (1989-2020)

\begin{tabular}{cccc}
\hline $\begin{array}{c}\text { Annual runoff } \\
\text { control rate/\% }\end{array}$ & $\begin{array}{c}\text { Design } \\
\text { rainfall/mm }\end{array}$ & $\begin{array}{c}\text { Annual runoff } \\
\text { control rate/\% }\end{array}$ & $\begin{array}{c}\text { Design } \\
\text { rainfall/mm }\end{array}$ \\
\hline $16 \%$ & 2.2 & $81 \%$ & 24.7 \\
$17 \%$ & 2.4 & $82 \%$ & 25.7 \\
$18 \%$ & 2.5 & $83 \%$ & 26.6 \\
$19 \%$ & 2.7 & $84 \%$ & 27.6 \\
$51 \%$ & 9.5 & $85 \%$ & 28.6 \\
$52 \%$ & 9.9 & $86 \%$ & 30.0 \\
$53 \%$ & 10.2 & $87 \%$ & 31.4 \\
$54 \%$ & 10.5 & $88 \%$ & 32.8 \\
\hline
\end{tabular}




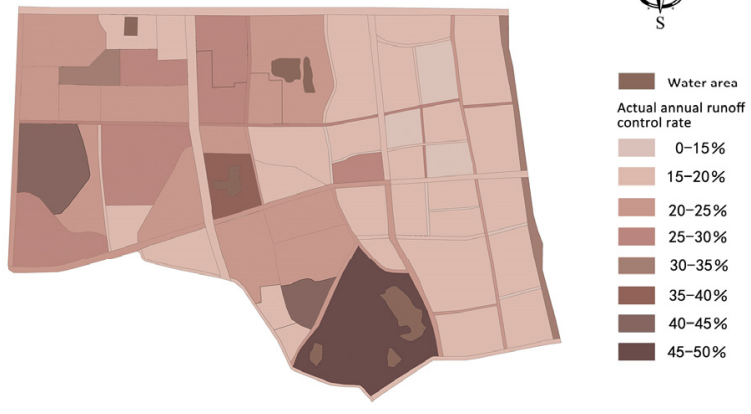

Fig. 7.Distribution chart of current annual runoff total control rate in the planning area

The terrain in the study area is relatively flat, with an average slope of $11.1 \%$. The soil is mainly red soil with little or no water permeability and poor permeability. The actual runoff control rate of each block is shown in Figure 7. The eastern part of the study area is dominated by old residential areas with high building density, with high degree of hardening and poor runoff control ability; the western part is dominated by newly built residential areas with low degree of hardening; the southern part is park green space, with strong runoff control ability. After conversion, the annual runoff control rate of the whole region is $23.7 \%$. Considering that Hengyang City is in the third interval of annual runoff control, with the index limit of $75 \%-85 \%$, and considering its comprehensive economic strength, the overall goal of planning control is determined to be $75 \%$.

\subsection{Decomposition of runoff management control indicators at the regulatory level}

Combined with the general goal of planning control mentioned in the overall planning level, the control regulations gradually decompose and refine the hard indicators proposed by the superior planning through comprehensive indicators and single indicators.

\subsubsection{Composite index decomposition}

According to the runoff control requirements of all kinds of land construction, reconstruction and expansion projects in the local sponge city construction technical guidelines, the preliminary index decomposition of each block was carried out. Some cities have not issued relevant technical guidelines, so the values can be used for reference according to the relevant guidelines of neighboring cities and combined with local actual conditions. This research region refers to the various requirements of land control mentioned in The Technical Guidelines for The Construction of Sponge Cities in Changsha. The specific assignment situation is shown in Table 3. According to the corresponding relationship of Table 1 and Table 2 and the area of each block, the runoff control volume of each block was calculated. After weighted calculation, the annual runoff control rate of the study area was $75.9 \%$, which met the mandatory index mentioned in the general plan level. The specific assignment of each block was shown in Figure 8.

Table 3. Preliminary Evaluation Table of Various Land Use Control Indicators

\begin{tabular}{ccc}
\hline Nature of the land & $\begin{array}{c}\text { New } \\
\text { construction }\end{array}$ & $\begin{array}{c}\text { reconstruc } \\
\text { tion }\end{array}$ \\
\hline Residential land & $80 \%$ & $65 \%$ \\
Public green space & $90 \%$ & $90 \%$ \\
Commercial service land & $75 \%$ & $65 \%$ \\
Educational and scientific research & $80 \%$ & $60 \%$ \\
land & $75 \%$ & $70 \%$ \\
Land for municipal facilities & $80 \%$ & $75 \%$ \\
Administrative office space & $60 \%$ & $55 \%$ \\
Urban road land & - & $45 \%$ \\
Land for railway & $70 \%$ & $65 \%$ \\
Square land & $100 \%$ & $100 \%$ \\
Water area & $70 \%$ & $60 \%$ \\
Industrial land & $70 \%$ & $60 \%$ \\
Logistics and warehousing land & $80 \%$ & $75 \%$ \\
Medical and sanitary land & &
\end{tabular}

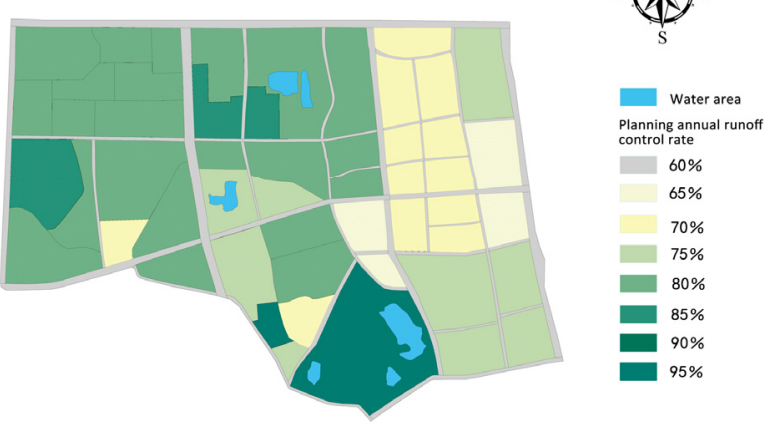

Fig. 8.Decomposition and assignment diagram of comprehensive index in planning area

\subsubsection{Single index decomposition}

In order to ensure the feasibility of index decomposition, the comprehensive index should be further decomposed into a single index. According to the current runoff management and control situation of each block in Figure 7, the sunken green space and permeable pavement should be selected as the main LID facilities in consideration of reconstruction cost, too little green space that can be reconstructed in the planning area and high building density. In the SWMM model, LID facility parameters are set as follows: surface stagnant water depth of permeable pavement is $15 \mathrm{~mm}$, Manning $\mathrm{N}$ value is 0.013 , surface slope is $1.5 \%$; The thickness of the surface layer is $150 \mathrm{~mm}$ and the pore ratio is 0.2 . The thickness of the gravel layer is $300 \mathrm{~mm}$, the pore ratio is 0.3 , the drainage coefficient of the bottom drainage layer is 3.3 , and the drainage index is 0.5 . The surface depth of sunken green space was $200 \mathrm{~mm}$, the vegetation cover 
coefficient was 0.8 , and the roughness was 0.25 . The sand and gravel thickness of the aquifer is $450 \mathrm{~mm}$, and the pore ratio is 0.75 . The thickness of the soil layer is $250 \mathrm{~mm}$ and the pore ratio is 0.3 .

At the same time, in order to solve the problems of tedious decomposition process and inaccurate results caused by repeated trial calculation of LID facility scale in SWMM, this study, with the help of MATLAB constraint optimization module, listed the constraint equation according to the basic data of underlying surface of various blocks collected in the early stage and the correlation of volume method, and the specific steps are as follows:

First, set area parameters for LID facilities preselected for each block, such as:

$$
S_{\text {Sunken green space }}=X_{1} ; \quad S_{\text {Permeable pavement }}=X_{2}
$$

Secondly, the comprehensive rainfall runoff coefficient of each block should be calculated, as shown in Formula 1.1:

$$
\varphi=\frac{\sum_{i=1}^{n} \varphi_{\mathrm{i}} s_{\mathrm{i}}}{\sum_{i=1}^{n} s_{\mathrm{i}}} \cdot \cdots \cdot 1.1
$$

Where $\varphi_{i}$ is the runoff coefficient of different catchment surface, which can be taken as the value in Table 4-3 of the Guide according to the actual situation of each block; $S_{\mathrm{i}}$ is the area of different catchment surface. According to the calculation relation mentioned in the volume method, the relevant constraints are listed.

Constraint Condition 1: Designed storage volume (Formula 1.2) :

$$
V_{1}=10 \varphi H F \quad \text { • • • } 1.2
$$

Actual storage volume (Formula 1.3) :

$$
V_{2}=\sum_{\mathrm{i}=1}^{\mathrm{n}} \mathrm{h}_{\mathrm{i}} \mathrm{p}_{\mathrm{i}} \mathrm{X}_{\mathrm{i}} \quad \cdots \cdot 1.3
$$

We want $V_{2}$ minus $V_{1}$ to be greater than or equal to 0 ; Where $H$ is the designed rainfall corresponding to the comprehensive control index of each block, $h$ is the designed storage depth of LID facility, and $p$ is the porosity of LID facility aquifer.

Constraint condition 2: Actual design rainfall (Formula 1.4) :

$$
H=V_{2} / 10 \varphi_{1} F \quad \bullet \cdot \bullet \cdot 1.4
$$

Then $H_{1}$ is required to be less than or equal to $H_{2}$, and $H_{2}$ value can be selected according to the corresponding relationship between the total annual runoff control rate and the designed rainfall. The corresponding total annual runoff control rate is slightly higher than that of $H_{1}$, in order to limit the search interval that meets the requirements.

Constraint 3: The maximum size of LID facilities in each block can be arranged (Formula 1.5) :

$$
0 \leq X_{1} \leq S_{1} ; \quad 0 \leq X_{2} \leq S_{2} \quad \bullet 1.5
$$

Where $S_{1}$ is the area of ordinary green space or other land that can be transformed into sunken green space; $S_{2}$ is the area of concrete or other hard pavement that can be transformed into permeable pavement. If other LID facilities are to be installed on the lot, the same can be done. Finally, the constraint optimization model was obtained (Figure 9). The constraint inequality was converted into a matrix and substituted into the MATLAB linear optimization module, and a single index was preliminarily obtained.

$$
\min F=\sum_{\mathrm{i}=1}^{\mathrm{n}} \mathrm{h}_{\mathrm{i}} \mathrm{p}_{\mathrm{i}} \mathrm{x}_{\mathrm{i}}\left\{\begin{array}{l}
V_{2}-V_{\mathrm{l}} \geq 0 \\
H \leq H_{2} \\
0 \leq X_{\mathrm{l}} \leq S_{\mathrm{l}} \\
0 \leq X_{2} \leq S_{2}
\end{array}\right.
$$

Fig. 9.Constrained optimization model

According to the size of LID facility obtained, it is put into the model to simulate and adjust, and finally individual control indexes of each block are obtained. A total of 91 sub-catchment areas were divided in this research area, with a large number of them, and only some indicators were presented. The specific results are shown in Table 4.

Introduction of constrained optimization module can be met quickly recessed the rate under this sub catchment area or permeable pavement rate (single index), If the calculated recessed green space rate or permeable pavement rate of special plots is too high, can limit the covering rate in constraint conditions, to substitute other LID facilities for its high part, and to get the LID size to meet the low scale of control, to prevent the scale facilities is too big, because the trial by the investment waste phenomenon. Thus, a single index satisfying the runoff control of each sub-catchment area can be preliminarily obtained, and on this basis, indexes can be adjusted according to the actual situation. According to the calculation, the actual volume of runoff

\begin{tabular}{|c|c|c|c|c|c|}
\hline \multirow[b]{2}{*}{$\begin{array}{l}\text { Plot } \\
\text { Numbe } \\
\text { rs }\end{array}$} & \multirow[b]{2}{*}{$\begin{array}{l}\text { Nature of the } \\
\text { land }\end{array}$} & \multicolumn{2}{|c|}{ Composite indicator } & \multicolumn{2}{|c|}{ Single parameter } \\
\hline & & $\begin{array}{l}\text { Annual runoff } \\
\text { control rate/\% }\end{array}$ & $\begin{array}{l}\text { Control volume } \\
\text { per unit area } \\
\left(\mathrm{m}^{3} \cdot \mathrm{m}^{-2}\right)\end{array}$ & $\begin{array}{c}\text { Sunken } \\
\text { green } \\
\text { rate/ } \\
\%\end{array}$ & $\begin{array}{c}\text { Permeable } \\
\text { pavement } \\
\text { rate/ } \\
\%\end{array}$ \\
\hline 1 & $\begin{array}{l}\text { Residential } \\
\text { land }\end{array}$ & 80 & 0.01313 & 43 & 60 \\
\hline 9 & $\begin{array}{l}\text { Land for } \\
\text { education }\end{array}$ & 85 & 0.01398 & 19 & 35 \\
\hline 14 & $\begin{array}{l}\text { Medical use of } \\
\text { land }\end{array}$ & 80 & 0.01451 & 40 & 30 \\
\hline 26 & The park land & 95 & 0.02311 & 21 & 35 \\
\hline 34 & $\begin{array}{l}\text { Residential } \\
\text { land }\end{array}$ & 70 & 0.01006 & 25 & 60 \\
\hline 46 & Road land & 60 & 0.00941 & 62 & 10 \\
\hline
\end{tabular}
control in the study area reached $45673.6 \mathrm{~m} 3$ after the decomposition index, and the corresponding annual total runoff control rate was $77.4 \%$, the total sunken green land rate was $37 \%$, and the total permeable pavement rate was $35.6 \%$, which met the requirements of runoff control in the planned area.

Table 4.Decomposition Results of Runoff Control Indicators for Some Plots 


\begin{tabular}{lccccc}
68 & Road land & 60 & 0.0095 & 68 & 10 \\
90 & Square land & 70 & 0.00751 & 6 & 30 \\
\hline
\end{tabular}

\section{Conclusion}

With the help of constraint optimization module of MATLAB and SWMM hydrological and hydraulic model, this paper puts forward a complete set of decomposition ideas and methods for decomposition and implementation of total runoff control rate in sponge city special planning according to mandatory index, comprehensive index and single index. This set of methods simplifies the complicated process of decomposing indexes by trial algorithm and model method, and reduces investment waste. Moreover, the index obtained by this method can not only meet the control rate, but also not excessively limit the layout of LID facilities; It can not only solve the problem of operability of plot planning, design and construction in the later period, but also avoid making the index too specific, restricting the development and construction of plot, leaving enough space for planning. The constrained optimization module can greatly simplify the process of calculating indexes by trial algorithm without model conditions. Because the model simulation focuses more on the actual process, the trial algorithm focuses more on the whole, and the indexes obtained by optimization also need to be adjusted in the simulation, which is more suitable for the traditional trial algorithm.

At the moment, the runoff pollution control target can be realized through controlling the total runoff mostly, so most of the area to total annual runoff control as the main planning index decomposition, but actually there will still be satisfied runoff control doesn't meet the pollution control situation, other scholars can on this basis, the perfect model data, using MATLAB modules related constraints runoff control target goal and the runoff pollution in consideration, in order to continue to improve the sponge city special planning; In addition, since the LAYOUT of LID facilities in THE SWMM model is not simulated in accordance with specific plans, other software is needed to further solve the index decomposition at the repair level.

\section{Reference}

1. Beijing University of Civil Engineering and Architecture. Technical Guide for Sponge City Construction-Construction of Rainwater System for Low Impact Development (Trial) [M]. Beijing: China Building Industry Press, 2015

2. Yang Ye, Shen Min, He Junchao, Zhu Jiang, Cao Pan. Study on optimization of decomposition method of annual runoff total control index in sponge city $[\mathrm{J}]$. Chinese Landscape Architecture, 2019,35(06):89-93.

3. Zhang Gaoyou, Gao Bin, Wang Xinliang. Deepening and implementation of annual runoff total control rate in sponge city in control regulations $[\mathrm{J}]$. China Water Supply and Drainage, 2018,34(06):1-5.

4. Minmin Huang, Shuanggen Jin. A methodology for simple 2-D inundation analysis in urban area using SWMM and GIS. 2019, 97(1):15-43.

5. Sui Zhang, LI Zhe. Simulation of Urban Rainstorm Waterlogging and Pipeline Network Drainage Process Based on SWMM. 2019, 1213(5)

6. F. Javier Martínez-Solano, Pedro L. Iglesias-Rey, Juan G. Saldarriaga, et al. Creation of an SWMM Toolkit for Its Application in Urban Drainage Networks Optimization. 2016, 8(6)

7. Tielan Huang, Yunpeng Wang, Jinlan Zhang. Simulation and Evaluation of Low Impact Development of Urban Residential District Based on SWMM and GIS. 2017, 74(1)

8. Jing Zhang, Yu Zhang, Shi-Jun Sun, et al. Analysis of the Effect of Low Impact Development on Urban Runoff Control Based on the SWMM Model. 2019, 96(sp1):62-67.

9. Gaurav V. Jain, Ritesh Agrawal, R.J. Bhanderi, et al. Estimation of sub-catchment area parameters for Storm Water Management Model (SWMM) using geo-informatics. 2016, 31(4):462-476.

10. N.A Zaghloul, M.A Abu Kiefa. Neural network solution of inverse parameters used in the sensitivity-calibration analyses of the SWMM model simulations. 2001, 32(7):587-595.

11. Tohru KANDA, Kazuo KANKI, Masahiro WATANABE, et al. ON MODEL PARAMETERS OF SWMM FOR SMALL URBAN DRAINAGE BASIN. 2001, 45:79-84.

12. Liu Pengfei, Huang Shiyuan, Liu Hui, Li Yingjie, Huang Xiao. Error analysis of annual runoff control rate estimated by linear interpolation method [J]. Water Resources Planning and Design, 2020(04):5558.

13. Liu Hui, Sun Bo, Zeng Fanyong, Xie Shuibo. Fast estimation of annual total runoff control rate and design rainfall based on linear interpolation method $[\mathrm{J}]$. Water Resources Planning and Design, 2019(10):41-43+148. 